\title{
Risk of Early Birth among Women with a Urinary Tract Infection: A Retrospective Cohort Study
}

\author{
Rebecca J. Baer, MPH ${ }^{1,2,3} \quad$ Nichole Nidey, $\mathrm{MS}^{4} \quad$ Gretchen Bandoli, $\mathrm{PhD}^{1} \quad$ Brittany D. Chambers, $\mathrm{PhD}^{3,5}$ \\ Christina D. Chambers, PhD ${ }^{1}$ Sky Feuer, $\mathrm{PhD}^{2,3}$ Deborah Karasek, PhD ${ }^{2,3}$ Scott P. Oltman, MS 3,5 \\ Larry Rand, MD ${ }^{2,3}$ Kelli K. Ryckman, PhD ${ }^{4,6}$ Laura L. Jelliffe-Pawlowski, PhD ${ }^{3,5}$
}

${ }^{1}$ Department of Pediatrics, University of California San Diego, La Jolla, California

2 Department of Obstetrics, Gynecology and Reproductive Sciences, University of California, San Francisco, California

${ }^{3}$ The California Preterm Birth Initiative, University of California San Francisco, San Francisco, California

${ }^{4}$ Department of Epidemiology, University of lowa, lowa City, lowa

${ }^{5}$ Department of Epidemiology and Biostatistics, University of California San Francisco, San Francisco, California

${ }^{6}$ Department of Pediatrics, University of lowa, lowa City, lowa

\author{
Address for correspondence Rebecca J. Baer, MPH, Department of \\ Pediatrics, University of California San Diego, 9500 Gilman Drive La \\ Jolla, CA 92093 `(e-mail: rjbaer@ucsd.edu).
}

Am J Perinatol Rep 2021;11:e5-e14.

\begin{abstract}
Keywords

- preterm birth

- early term birth

- urinary tract infection

- bacterial species

- trimester of infection

Objective The aim of the study is to evaluate the risk of preterm birth (PTB, $<37$ weeks) and early term (37 and 38 weeks) birth among women with an emergency department (ED) visit or hospitalization with a urinary tract infection (UTI) by trimester of pregnancy.

Methods The primary sample was selected from births in California between 2011 and 2017. UTIs were identified from the ED or hospital discharge records. Risk of PTB, by subtype, and early term birth were evaluated by trimester of pregnancy and by type of visit using log-linear regression. Risk ratios were adjusted for maternal factors. Antibiotic usage was examined in a population of privately insured women from lowa. Results Women with a UTI during pregnancy were at elevated risk of a birth $<32$ weeks, 32 to 36 weeks, and 37 to 38 weeks (adjusted risk ratios [aRRs] 1.1-1.4). Of the women with a diagnostic code for multiple bacterial species, $28.8 \%$ had a PTB. A UTI diagnosis elevated risk of PTB regardless of antibiotic treatment (aRR 1.4 for treated, aRR 1.5 for untreated).

Conclusion UTIs are associated with early birth. This association is present regardless of the trimester of pregnancy, type of PTB, and antibiotic treatment.
\end{abstract}

Urinary tract infections (UTIs) are frequent during pregnancy, affecting as many as $8 \%$ of pregnant women. ${ }^{1}$ Physical changes during pregnancy such as increased bladder volume and decreased bladder tone, as well as a change in the vaginal flora increase risk of a UTI. ${ }^{1,2}$ Infection often begins as asymptomatic bacteriuria, which progresses to a lower tract infection (acute cystitis) in $30 \%$ of patients, and can lead to upper tract

received

April 1, 2020

accepted

October 2, 2020
DOI https://doi.org/

10.1055/s-0040-1721668

ISSN 2157-6998. infection (acute pyelonephritis) in up to $50 \%$ of patients. ${ }^{1}$ Current guidelines recommend testing for bacteriuria during early pregnancy. ${ }^{3-6}$ Treatment with a pregnancy-appropriate antibiotic is recommended, regardless of symptoms. ${ }^{1,7}$

UTIs have been associated with preterm birth (PTB) $(<37$ weeks' gestation) in some studies. ${ }^{8-12}$ However, these findings have not been consistently replicated. ${ }^{13,14}$ The suggested
(C) 2021. The Author(s).

This is an open access article published by Thieme under the terms of the Creative Commons Attribution License, permitting unrestricted use, distribution, and reproduction so long as the original work is properly cited. (https://creativecommons.org/licenses/by/4.0/) Georg Thieme Verlag KG, Rüdigerstraße 14, 70469 Stuttgart, Germany 
pathophysiology of the relationship is that the bacteria ascends to the uterus, causing an inflammatory reaction, which leads to uterine contractions and chorioamniotic membrane degradation. ${ }^{15}$ Untreated group B Streptococcus in early pregnancy has been associated with chorioamnionitis. ${ }^{16}$ There have been few studies evaluating the association between UTIs and PTB by spontaneous or medically indicated causes, however, the Cardiff Birth Survey found that women with asymptomatic bacteriuria had two-times higher odds of a medically indicated PTB but not spontaneous. ${ }^{17}$ It has been postulated that treating asymptomatic bacteriuria in pregnancy decreases the risk of PTB by

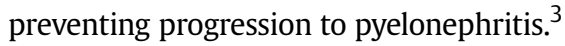

It is unknown how the gestational age of the pregnancy at the time of the infection impacts the risk of PTB. Additionally, the type of PTB (early, late, spontaneous, provider initiated) and species causing the UTI have not been rigorously evaluated. Here, we evaluate the risk of PTB by subtype and early term birth (37 and 38 weeks' gestation) among women with an emergency department (ED) visit or hospitalization with a UTI by trimester of pregnancy.

\section{Methods}

The primary sample was drawn from all California live born infants between 2011 and 2017. Birth certificates, maintained by California Vital Statistics, were linked to a hospital discharge, $E D$, and ambulatory surgery records maintained by the California Office of Statewide Health Planning and Development. These databases contain detailed information on maternal and infant characteristics, hospital discharge diagnoses, and procedures. Hospital discharge, ED, and ambulatory surgery files provided diagnoses and procedure codes based on the International Classification of Diseases, 9th Revision, Clinical Modification (ICD-9) and International Classification of Diseases, 10th Revision, Clinical Modification (ICD-10) as reported to the California Office of Statewide Health Planning and Development by the hospitals. The study sample restricted to singletons born between 22 and 44 weeks' gestation, with linked birth records for mother and infant, and infants without chromosomal abnormalities or major structural birth defects. Structural birth defects for the study were considered "major" if determined by clinical review as causing major morbidity and mortality that would likely be identified in the hospital at birth or lead to hospitalization during the first year of life. ${ }^{18}$ Finally, women with a maternal diagnostic code for asymptomatic bacteriuria were excluded from the sample (- Fig. 1, -Appendix 1).

UTI was defined as a maternal diagnostic code for a UTI or pyelonephritis (-Appendix 1). ${ }^{19}$ Diagnoses were obtained from hospital discharge, ED, or ambulatory surgery records during pregnancy or on the birth record. Timing of infection was examined by trimester $(0-13$ completed weeks $=$ first trimester, 14-26 completed weeks = second trimester, 27-38 completed weeks $=$ third trimester) or birth record. Women who had more than one visit with an indication of a UTI during a single trimester were considered to have a persistent UTI. Women with an indication of a UTI during more than one trimester were considered to have a recurrent UTI. If they had

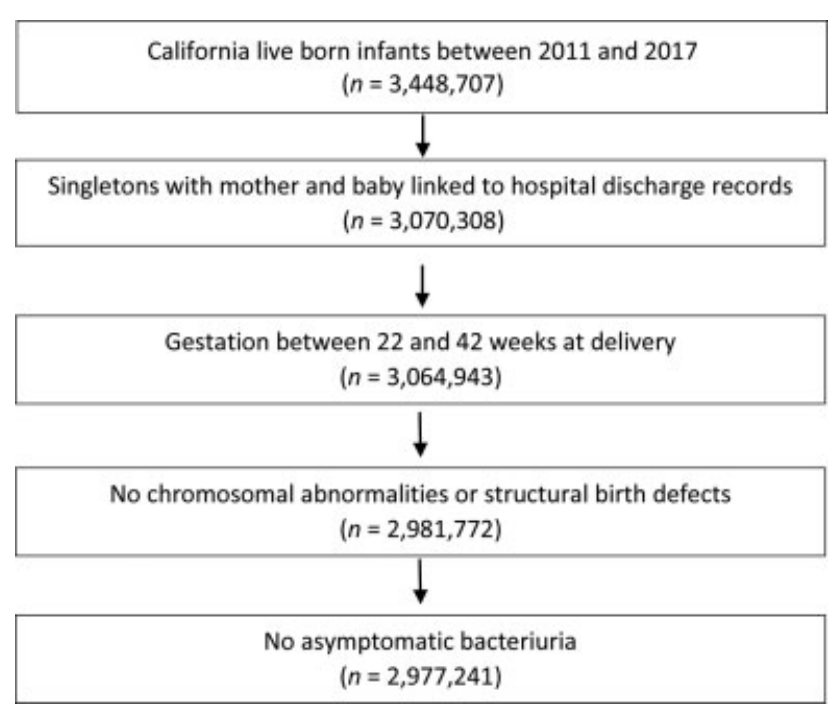

Fig. 1 Sample selection.

both persistent and recurrent infections, they were only coded as persistent. Women with a single diagnostic code for a UTI were examined by the trimester of the diagnosis. Women with only a diagnostic code for a UTI on the birth record were examined separately. Type of visit was categorized as an ED visit or hospital admission. Records also included ambulatory surgery, however, due to small numbers this type of visit was not evaluated separately, although was included in overall numbers. When available, organism was identified using diagnostic codes.

Best obstetric estimate of gestation at birth was obtained from birth certificate records. Gestational age at delivery was categorized as before 32 weeks, between 32 and 36 weeks, before 37 weeks (preterm), between 37 and 38 weeks (early term), and between 39 and 42 weeks (full term) gestation. PTB was defined as spontaneous or provider initiated. Spontaneous PTB was further subdivided into preterm premature rupture of the membranes (PPROM) or premature spontaneous labor with intact membranes. Consistent with previous reports, ${ }^{20}$ all pregnancies with delivery before 37 weeks with indication of PPROM in the infant's birth certificate or mother's hospital discharge records were included in the PPROM group. Women with no indication of PPROM who delivered before 37 weeks who had a code for premature labor or tocolytic medication on birth certificate or hospital discharge records were included in the spontaneous labor with intact membranes group. Pregnancies resulting in provider-initiated PTB were those without PPROM, premature labor, or tocolytic administration who had a code for "medical induction" or "artificial rupture of membranes" on birth certificate or hospital discharge records. Additionally, provider-initiated PTBs included those for which there was a cesarean delivery without any of the aforementioned codes.

Maternal characteristics for women with a birth less than 37 weeks, 37 to 38 weeks, and 39 to 42 weeks were compared using chi-square statistics. Potential confounders selected based on previous literature. ${ }^{20}$ Confounders from birth 
certificate records included: race or ethnicity, maternal age at delivery, insurance coverage for delivery, maternal education, parity, adequacy of prenatal care, ${ }^{21}$ prepregnancy body mass index (BMI, calculated from prepregnancy weight and height), smoking status during pregnancy, and previous PTB. Additional potential confounders selected from discharge diagnoses including those that were noted by the coding hospital as "complicating pregnancy": hypertensive disorder, diabetes, and drug or alcohol abuse or dependence (-Appendix 1).

Poisson log-linear regression was used to calculate relative risks (RRs) and 95\% confidence intervals (95\% confidence interval [CI]) for birth $<32$ weeks, 32 to 36 weeks, and 37 and 38 weeks. Referent populations for the analyses were selected based on the timing of the outcome to avoid an immortal time bias: when examining birth $<32$ weeks, women without a UTI during the first 31 weeks of pregnancy served as the referent population; when examining birth from 32 to 36 weeks and any less than 37 weeks, women without a UTI during the first 36 weeks of pregnancy served as the referent population; when examining birth between 37 and 38 weeks, women without a UTI during the first 38 weeks of pregnancy served as the referent population. Univariable and multivariable risk calculations were made. Multivariable models were adjusted for potential confounders listed above. The multivariable model for UTI in the birth admission only was also adjusted for the mother's length of hospital stay.

Risk ratios were estimated by trimester of infection and type of visit (ED or hospital admission). Risks were also estimated for type of PTB: PPROM, spontaneous labor, and provider initiated PTB. Risk estimates were not performed for births $<32$ weeks among women with a UTI in their third trimester.

Due to limitations regarding information from outpatient clinics and antibiotic usage in the California dataset, the analyses were replicated in a database from the state of Iowa. Pregnant privately insured women who delivered between 2005 and $2015(n=26,350)$ contained in a claims dataset including inpatient and outpatient data were selected for the analysisQ4. The database was queried for women who had an ICD-9 or ICD-10 diagnostic code for a UTI within 6 months of delivery. Infants born preterm were identified by ICD- 9 and ICD-10 codes (-Appendix 1). Logistic regression was used to calculate RRs and 95\% CIs for PTB using women without an indication of a UTI and a birth greater than 37 completed weeks as the referent population. Univariable and multivariable odds calculations were made. In multivariable models, risks were adjusted for confounders available in the dataset, which included maternal age at delivery, gestational diabetes, and gestational hypertension. Women with a UTI were queried for antibiotic use within 6 months prior to delivery. Antibiotics were defined as appropriate for a UTI during pregnancy, ${ }^{1,22}$ however, it was unknown if the medication was prescribed for a UTI.

All analyses were performed using Statistical Analysis Software version 9.4 (Cary, NC). Methods and protocols for the study were approved by the Committee for the Protection of Human Subjects within the Health and Human Services Agency of the State of California. For the Iowa population, this project was deemed exempt from IRB due to being an unidentifiable dataset.

\section{Results}

Of the 2,977,241 California births in our sample, 189,321 (6.4\%) occurred $<37$ weeks, 723,930 (24.3\%) were 37 to 38 weeks, and 2,063,990 (69.3\%) were 39 to 42 weeks. Nearly $50 \%$ (49.0\%) of the sample was Hispanic, $78.1 \%$ was between 18 and 34 years of age at delivery, and $46.0 \%$ used public insurance as the payer for delivery. Women in these three gestational age groups significantly differed by all measured factors: race or ethnicity, age at delivery, payment for delivery, education, parity, adequacy of prenatal care, prepregnancy BMI, diabetes, hypertension, smoking, drug/alcohol use, anemia, mental illness, and previous PTB (-Table 1).

Of the California sample, 160,861 (5.4\%) had an indication of a UTI during pregnancy. Of the 85,908 women who had a UTI in the first 31 weeks of pregnancy and either delivered $<32$ weeks or between 39 and 42 weeks, 1,773 (2.1\%) had a birth $<32$ weeks versus $0.9 \%$ of the $1,996,519$ women who did not have a UTI in this time period (adjusted risk ratio [aRR] 1.6, 95\% CI 1.5-1.7) (- Table 2, - Supplementary Table S1). Risks were also elevated for births between 32 and 36 weeks (aRR 1.4, 95\% CI 1.3, 1.4), any birth $<37$ weeks (aRR 1.4, 95\% CI 1.3-1.4), and between 37 and 38 weeks (aRR 1.1, 95\% CI 1.1-1.2) (-Table 2; - Supplementary Tables S1-S3 and S4).

Women with a UTI only in the first trimester were at elevated risk of a birth $<32$ weeks (aRR 1.4, 95\% CI 1.3-1.6), 32 to 36 weeks (aRR 1.1,95\% CI 1.1-1.3), any birth $<37$ weeks (aRR 1.2, 95\% CI 1.2-1.3) and 37 and 38 weeks (aRR 1.1, 95\% CI 1.1-1.1). After adjustment, little difference was seen in the risk calculations between women seen in the ED and women admitted to the hospital with a first trimester UTI ( - Table 2;

\section{- Supplementary Tables S1-S3 and S4).}

Women with a second trimester UTI were at elevated risk of a birth $<32$ weeks, 32 to 36 weeks, and 37 to 38 weeks (aRRs 1.7, 1.3, 1.1, respectively) (- Table 2; - Supplementary Tables S1, S2, and S4). Of the 4,123 women who were hospitalized in the second trimester with a UTI and delivered $<32$ weeks or between 39 and 42 weeks, 3.7\% delivered $<32$ weeks versus $0.9 \%$ of women who did not have a UTI (aRR 2.8 , 95\% CI 2.4-3.3) (-Table 2, - Supplementary Table S1). Women who were hospitalized with a third trimester UTI were at elevated risk of a birth between 32 to 36 weeks and 37 to 38 weeks (aRRs 2.1 and 1.3, respectively), whereas an ED visit with a third trimester UTI did not elevate the risk of a PTB. Women with a persistent or recurrent UTI were at elevated risks of birth $<32$ weeks, 32 to 36 weeks, and 37 to 38 weeks (aRRs 1.2-2.3) (-Table 2).

Women in the California population who did not have a UTI diagnosis in a predelivery record but did have a UTI in the birth record were at increased risk of early birth. Notably, $28.7 \%$ of the 3,068 women who had a UTI diagnosis on the birth record only delivered $<32$ weeks compared with $0.9 \%$ of women who did not have a UTI (aRR 10.3, 95\% CI 9.6-11.0).

Of the 7,442 women in the California population who developed pyelonephritis in the first 36 weeks of pregnancy and 
e8 Risk of Early Birth among Women with a UTI Baer et al.

Table 1 Sample characteristics among women from CaliforniaQ5

\begin{tabular}{|c|c|c|c|}
\hline & Less than 37 & $37-38$ & $39-42$ \\
\hline Sample & 189,321 & 723,930 & $2,063,990$ \\
\hline \multicolumn{4}{|l|}{ Race or ethnicity ${ }^{\mathrm{a}}$} \\
\hline White non-Hispanic & $41,987(22.2)$ & $160,354(22.2)$ & $588,083(28.5)$ \\
\hline Hispanic & $96,574(51.0)$ & $373,651(51.6)$ & $988,657(47.9)$ \\
\hline Black non-Hispanic & $13,625(7.2)$ & $36,961(5.1)$ & $95,680(4.6)$ \\
\hline Asian & $26,952(14.2)$ & $119,024(16.4)$ & $288,904(14.0)$ \\
\hline Other & $10,183(5.4)$ & $33,940(4.7)$ & $102,665(5.0)$ \\
\hline \multicolumn{4}{|l|}{ Age at delivery (years) ${ }^{\mathrm{a}}$} \\
\hline Less than 18 & $3,709(2.0)$ & $12,254(1.7)$ & $34,190(1.7)$ \\
\hline $18-34$ & $139,680(73.8)$ & 556,615 (76.9) & $1,628,440$ (78.9) \\
\hline More than 34 & $45,913(24.3)$ & $155,031(21.4)$ & $401,298(19.4)$ \\
\hline Missing & $19(0.0)$ & $30(0.0)$ & $62(0.0)$ \\
\hline \multicolumn{4}{|l|}{ Payment for delivery ${ }^{a}$} \\
\hline Private insurance & $83,937(44.3)$ & $329,179(45.5)$ & $1,006,356(48.8)$ \\
\hline Medi-Cal $^{b}$ & $93,884(49.6)$ & $348,405(48.1)$ & 926,277 (44.9) \\
\hline Other & $11,500(6.1)$ & $46,346(6.4)$ & $131,357(6.4)$ \\
\hline \multicolumn{4}{|l|}{ Maternal education ${ }^{\text {a }}$ (years) } \\
\hline Less than 12 & $36,920(19.5)$ & $135,882(18.8)$ & $336,949(16.3)$ \\
\hline 12 & $48,526(25.6)$ & $181,190(25.0)$ & $497,945(24.1)$ \\
\hline More than 12 & $92,153(50.3)$ & $377,098(52.1)$ & $1,141,832(55.3)$ \\
\hline Missing & $8,722(4.6)$ & $29,760(4.1)$ & $87,264(4.2)$ \\
\hline \multicolumn{4}{|l|}{ Parity $^{\text {a }}$} \\
\hline Nulliparous & $72,168(38.1)$ & $247,454(34.2)$ & $829,247(40.2)$ \\
\hline Multiparous & $116,939(61.8)$ & $476,041(65.8)$ & $1,233,452(59.8)$ \\
\hline Missing & $214(0.1)$ & $432(0.1)$ & $1,291(0.1)$ \\
\hline \multicolumn{4}{|l|}{ Adequacy of prenatal care ${ }^{\mathrm{a}, \mathrm{c}}$} \\
\hline Adequate plus/adequate & $145,541(76.9)$ & $547,290(75.6)$ & $1,493,585(72.4)$ \\
\hline Intermediate & $15,815(8.4)$ & $87,980(12.2)$ & $308,567(15.0)$ \\
\hline Inadequate & $22,045(11.6)$ & $72,655(10.0)$ & $218,917(10.6)$ \\
\hline Missing & $5,920(3.1)$ & $16,005(2.2)$ & $42,921(2.1)$ \\
\hline \multicolumn{4}{|l|}{ Prepregnancy body mass index ${ }^{a}$} \\
\hline Less than $18.5 \mathrm{~m} / \mathrm{kg}^{2}$ & $7,736(4.1)$ & $30,638(4.2)$ & $74,318(3.6)$ \\
\hline $18.5-24.9 \mathrm{~m} / \mathrm{kg}^{2}$ & $77,152(40.8)$ & $324,618(44.8)$ & $949,311(46.0)$ \\
\hline $25.0-29.9 \mathrm{~m} / \mathrm{kg}^{2}$ & $46,934(24.8)$ & $179,282(24.8)$ & $520,478(25.2)$ \\
\hline $30.0 \mathrm{~m} / \mathrm{kg}^{2}$ or more & $47,544(25.1)$ & $158,540(21.9)$ & $436,954(21.2)$ \\
\hline Missing & $9,955(5.3)$ & $30,852(4.3)$ & $82,929(4.0)$ \\
\hline Any diabetes ${ }^{\mathrm{a}}$ & $35,200(18.6)$ & $104,828(14.5)$ & $200,416(9.7)$ \\
\hline Any hypertension ${ }^{\mathrm{a}}$ & $45,630(24.1)$ & $95,087(13.1)$ & $131,634(6.4)$ \\
\hline Smoked ${ }^{\mathrm{a}}$ & $9,756(5.2)$ & $22,633(3.1)$ & $57,416(2.8)$ \\
\hline Drug/alcohol use & $9,397(5.0)$ & $16,307(2.3)$ & $34,355(1.7)$ \\
\hline Previous preterm birth ${ }^{\mathrm{a}}$ & $8,198(4.3)$ & $10,353(1.4)$ & $12,135(0.6)$ \\
\hline
\end{tabular}

${ }^{\mathrm{a}} \mathrm{p}<0.0001$ by Chi-square.

${ }^{\mathrm{b} C a l i f o r n i a ' s ~ M e d i c a i d, ~ h e a l t h ~ c o v e r a g e ~ f o r ~ l o w ~ i n c o m e ~ p e r s o n s . ~}$

'per Kotelchuck. ${ }^{21}$ 
Table 2 Risk of preterm and early term birth among women from California with an emergency room visit or hospitalization for a urinary tract infection by trimester of pregnancy

\begin{tabular}{|c|c|c|c|c|}
\hline \multirow[t]{3}{*}{ Subtype } & \multicolumn{4}{|c|}{ Gestation at birth (weeks) } \\
\hline & $<32$ & $32-36$ & Any $<37$ & 37 and 38 \\
\hline & aRR $(95 \% \mathrm{Cl})$ & aRR $(95 \% \mathrm{Cl})$ & aRR $(95 \% \mathrm{Cl})$ & aRR $(95 \% \mathrm{Cl})$ \\
\hline Any urinary tract infection in pregnancy & $1.6(1.5,1.7)$ & $1.4(1.3,1.4)$ & $1.4(1.3,1.4)$ & $1.1(1.1,1.2)$ \\
\hline First trimester only & $1.4(1.3,1.6)$ & $1.2(1.2,1.3)$ & $1.2(1.2,1.3)$ & $1.1(1.1,1.1)$ \\
\hline ED visit & $1.4(1.3,1.5)$ & $1.3(1.2,1.5)$ & $1.2(1.2,1.3)$ & $1.1(1.1,1.1)$ \\
\hline Hospitalized & $2.2(1.7,2.9)$ & $1.4(1.3,1.6)$ & $1.4(1.2,1.5)$ & $1.1(1.0,1.2)$ \\
\hline Second trimester only & $1.7(1.5,1.8)$ & $1.3(1.2,1.3)$ & $1.3(1.3,1.4)$ & $1.1(1.1,1.1)$ \\
\hline ED visit & $1.4(1.3,1.6)$ & $1.3(1.2,1.3)$ & $1.3(1.2,1.3)$ & $1.1(1.1,1.1)$ \\
\hline Hospitalized & $2.8(2.4,3.3)$ & $1.5(1.4,1.6)$ & $1.6(1.4,1.7)$ & $1.1(1.1,1.2)$ \\
\hline Third trimester only & a & $1.6(1.5,1.7)$ & $1.5(1.4,1.6)$ & $1.2(1.2,1.2)$ \\
\hline ED visit & a & $1.1(1.0,1.2)$ & $1.1(1.0,1.2)$ & $1.1(1.0,1.1)$ \\
\hline Hospitalized & a & $2.1(2.0,2.2)$ & $2.0(1.8,2.1)$ & $1.3(1.3,1.4)$ \\
\hline Birth hospitalization only & $10.3(9.6,11.0)$ & $3.2(3.0,3.3)$ & $3.1(3.0,3.3)$ & $1.1(1.1,1.1)$ \\
\hline Persistent & $1.7(1.5,1.9)$ & $1.4(1.4,1.5)$ & $1.4(1.4,1.5)$ & $1.2(1.2,1.2)$ \\
\hline Recurrent & $2.3(2.1,2.6)$ & $1.6(1.5,1.7)$ & $1.6(1.5,1.7)$ & $1.2(1.2,1.3)$ \\
\hline Pyelonephritis & $1.8(1.5,2.1)$ & $1.5(1.4,1.6)$ & $1.5(1.4,1.6)$ & $1.1(1.1,1.1)$ \\
\hline
\end{tabular}

Abbreviations: aRR, adjusted risk ratio; $\mathrm{Cl}$, confidence interval; $\mathrm{ED}$, emergency department; UTI, urinary tract infection.

Note: Bold when $p<0.05$; aRR: adjusted for race/ethnicity, age, education, payer for delivery, body mass index, parity, smoking, drug/alcohol dependence/abuse, diabetes, hypertension (including preeclampsia), previous preterm birth. Birth hospitalization only also adjusted for length of hospital stay; For each time period with "only," woman did not have more than one ED visit of hospitalization; Persistent = more than one ED visit or hospitalization in a time period; Recurrent = UTI in more than one time period; If they had both persistent and recurrent, they were coded as persistent.

${ }^{\mathrm{a}}$ Third trimester calculations were not made for delivery $<32 \mathrm{wk}$.

delivered preterm or between 39 and 42 weeks, $14.9 \%$ had a PTB compared with $8.1 \%$ of women without pyelonephritis or UTI (aRR 1.5, 95\% CI 1.4-1.6) (- Table 2, - Supplementary Table S3).

Of the women with an indication of a UTI in the California dataset, $21.1 \%$ had a code for an organism that could be associated with the UTI. The most commonly documented organism was Escherichia coli $(n=3,918)$. When examining the rate of PTB by organism, women with an organism code had a PTB rate of $15.2 \%$ or higher, whereas the PTB rate for women without a documented organism code was $9.2 \%$. The highest rate of PTB was among women infected with a single species was for women infected with Enterococcus species (41 of $144,28.5 \%$ ). The rate of PTB was $28.8 \%$ for woman with more than one bacterial species ( $\mathbf{- T a b l e ~} \mathbf{3}$ ).

When considering the type of PTB, women were consistently at increased risk of spontaneous preterm labor, either $<32$ weeks or 32 to 36 weeks (- Supplementary Tables S1 and S2). Women hospitalized with a second trimester UTI were at 2.8-fold higher risk of a birth $<32$ weeks with PPROM, 3.2-times higher risk of a birth $<32$ weeks with spontaneous labor with intact membranes, and 2.3-fold higher risk of birth $<32$ weeks due to provider initiation compared with women without a UTI during pregnancy (-Supplementary Table S1).

In the Iowa dataset, 4,492 (17.1\%) women had a UTI within 6 months prior to delivery. After adjustments, women with a
Table 3 Rate of preterm birth by organism among women from California

\begin{tabular}{|l|l|l|}
\hline \multirow{2}{*}{} & \multicolumn{2}{|l|}{ Preterm } \\
\cline { 2 - 3 } & $n$ & $\%$ \\
\hline Escherichia coli $(n=3,918)$ & 597 & 15.2 \\
\hline Klebsiella $(n=243)$ & 52 & 21.4 \\
\hline Proteus $(n=119)$ & 21 & 17.7 \\
\hline Pseudomonas $(n=44)$ & 8 & 18.2 \\
\hline Streptococcus $(n=320)$ & 75 & 23.4 \\
\hline Enterococcus $(n=144)$ & 41 & 28.5 \\
\hline Staphylococcus $(n=149)$ & 32 & 21.5 \\
\hline Multiple species $(n=146)$ & 42 & 28.8 \\
\hline Other/Unspecified ICD-9/10 code $(n=4,800)$ & 824 & 17.2 \\
\hline No organism ICD-9/10 code $(n=126,909)$ & 11,716 & 9.2 \\
\hline
\end{tabular}

Abbreviation: ICD, Indian Classification of Disease-Ninth Revision.

UTI were 1.4-times more likely to have a PTB than women without a UTI (95\% CI 1.2-1.6). Over $90 \%$ of women with a UTI had a record of an antibiotic prescribed within 6 months prior to delivery. When examining the risk of PTB among women with antibiotic use, treated women were 1.4-times more likely to have a PTB than women without a UTI (95\% CI 
Table 4 Risk of preterm birth among women from lowa with an outpatient visit for a urinary tract infection within 6 months of delivery

\begin{tabular}{|c|c|c|}
\hline & Any $<37$ wk & $\geq 37 \mathrm{wk}$ \\
\hline & $n$ (row \%) & $n$ (row \%) \\
\hline & RR (95\% Cl) & RR (95\% Cl) \\
\hline & aRR (95\% Cl) & aRR (95\% Cl) \\
\hline Sample $(n=26,350)$ & $1,587(6.0)$ & $24,763(94.0)$ \\
\hline \multicolumn{3}{|c|}{ Outpatient urinary tract infection } \\
\hline \multirow[t]{2}{*}{ No $(n=21,858)$} & \multirow[t]{2}{*}{$1,231(5.6)$} & $20,627(94.4)$ \\
\hline & & Reference \\
\hline \multirow[t]{3}{*}{ Yes $(n=4,492)$} & $356(7.9)$ & \multirow[t]{3}{*}{$4,136(92.1)$} \\
\hline & $1.4(1.3,1.6)$ & \\
\hline & $1.4(1.2,1.6)$ & \\
\hline \multirow{3}{*}{$\begin{array}{l}\text { Antibiotic prescribed } \\
(n=4,156)\end{array}$} & 328 (7.9) & \multirow[t]{3}{*}{$3,828(92.1)$} \\
\hline & $1.4(1.2,1.6)$ & \\
\hline & $1.4(1.2,1.5)$ & \\
\hline \multirow{3}{*}{$\begin{array}{l}\text { No antibiotic on } \\
\text { record }(n=336)\end{array}$} & $28(8.3)$ & \multirow[t]{3}{*}{$308(91.7)$} \\
\hline & $1.5(1.0,2.2)$ & \\
\hline & $1.5(1.0,2.2)$ & \\
\hline
\end{tabular}

Abbreviations: aRR, adjusted risk ratio; $\mathrm{Cl}$, confidence interval; $\mathrm{RR}$, relative risk.

Note: Bold when $p<0.05$; aRR: adjusted for age, gestational diabetes, and gestational hypertension.

1.2-1.5). Women who did not have a record of an antibiotic prescription were at an adjusted 1.5-times higher risk of a PTB than women without a UTI in the 6 months prior to delivery (95\% CI 1.0-2.2, $p<0.05$ ) (-Table 4).

\section{Discussion}

In this large California population-based sample, a UTI increased the risk of a PTB, particularly a spontaneous PTB. This risk was elevated regardless of the trimester of pregnancy, but women hospitalized with a UTI during their second trimester were at greatest risk, suggesting that more severe infections further elevate the risk during this time period. Of particular concern, after adjustments, women hospitalized with a UTI during their second trimester were at threefold higher risk of a birth $<32$ weeks. The diagnosis of pyelonephritis did not show higher risk of a PTB than the diagnosis of a UTI. Treatment of the UTI did not dramatically reduce the odds of PTB in our Iowa sample.

We are not the first to demonstrate an association between UTIs and PTB. ${ }^{8-12}$ Other population-based studies have found the odds of PTB are two-times higher for women with a UTI during pregnancy. Here, we calculated RRs and found women with a UTI during pregnancy were 1.4-times more likely to experience a PTB after adjusting for maternal factors. Studies examining early PTB (defined as $<34$ weeks in other studies, $<32$ weeks in our study) have reported mixed findings. In a population-based study out of Israel, Mazor-Dray and colleagues ${ }^{11}$ found women with a UTI were at two-times higher odds of a birth $<34$ weeks whereas Chen and colleagues found no association in a Taiwanese population. ${ }^{11,13}$ Few other population-based studies have examined timing of UTI and risk of preterm delivery. Morken and colleagues did not find an association between a UTI before 17 weeks' gestation and PTB. ${ }^{14}$ Women with UTIs early in pregnancy in our study also had an increased risk of PTB (1.2-fold increased risk for infection in the first trimester, 1.2-fold increased risk for infection in the second trimester). Again, few others have examined the association between UTIs and spontaneous or provider initiated PTB. In the Cardiff Birth Survey, women with asymptomatic bacteriuria had two-times higher odds of a medically indicated PTB but not spontaneous. ${ }^{17}$ Our study generally found a greater association with spontaneous PTB, but women with a UTI during some time points in pregnancy were also at increased risk of a provider initiated PTB. It is notable that we are unique in our evaluation of the risk of an early term (37 and 38 weeks) birth; our data found that women with a UTI during pregnancy were at slightly increased risk (aRR 1.1) of an early term birth.

Findings regarding the association between pyelonephritis and PTB have also been discordant. Farkash and colleagues showed an increased odds of PTB for women with pyelonephritis (OR 2.6) ${ }^{10}$ and Bánhidy and colleagues demonstrated greater risk of PTB with greater severity of infection. ${ }^{9}$ Conversely, Chen and colleagues did not find an association between women with pyelonephritis and PTB risk. We showed an association between pyelonephritis and PTB, but the risk was not elevated over acute cystitis. However, we did show that women hospitalized with a UTI during their second trimester are at greatest risk of PTB, suggesting that more severe infections (hospitalized) further elevate the risk during this time period.

There are several explanations for the differences between our findings and those of others. Our population may have been at higher risk than other population-based studies. In the low-risk Scandinavian population examined by Morken and colleagues, the association with UTI and PTB was negative. ${ }^{14}$ Our diverse population may have been at higher risk for PTB. Like Chen and colleagues, we obtained UTI diagnosis via ICD-9 codes. ${ }^{13}$ However, Chen and colleagues considered UTIs within 9 months of deliveries. For women with a PTB, this may include UTIs that occurred prior to pregnancy, perhaps contributing to their negative findings. Further, Chen was identifying women from ambulatory care settings. It is possible that women in our study had more severe infections because they were presenting at the ED or were hospitalized.

Our findings support a leading hypothesis of one cause of PTB. Infection may lead to early delivery when bacteria ascend to the uterus and stimulate secretion of inflammatory cytokines which have been associated with different subtypes of PTB. ${ }^{15,23,24}$ It has been suggested that some antibiotics may prevent PTB. ${ }^{9,10}$ Treatment of asymptomatic bacteriuria is recommended based on the assumption that it can lead to better birth outcomes. ${ }^{5,6}$ However, similar to ours, several studies have suggested that the risk of early delivery among women with a UTI persists despite treatment. ${ }^{11,25,26}$ We 
showed that women were at elevated risk of PTB regardless of treatment when the UTI was diagnosed at an inpatient or outpatient visit within 6 months of delivery. This suggests that treatment may not adequately halt the inflammatory cascade leading to PTB, and that infection early in pregnancy is still associated with early parturition months later. Our evaluation of species causing the UTI suggests that the risk of PTB may differ by causal agent. As bacterial species have differing pathogenic properties, these differences may further suggest pathophysiology of UTI and PTB.

Our study has many strengths that contribute to the knowledge of the relationship between UTIs and preterm and early term birth. Our California population is large and diverse, allowing for examination of PTB by subtype, by trimester of infection, and by type of encounter with health care. The linked database contains information that permitted adjustment of the risk that was not possible in many of the previous studies. Comparing our ascertainment with other population-based studies suggests we have good ascertainment of the diagnosis of UTIs. In previous studies, 2.3 to $5.7 \%$ of pregnant women experience a UTI, while $5.4 \%$ of our population experienced this complication. ${ }^{9,11}$ We were able to replicate our findings in a sample of women in Iowa and evaluate antibiotic usage in this population.

Despite these strengths, using an administrative database also has limitations that require appropriate interpretation. Although the Californian population had timing of diagnosis at an ED or hospital, this is likely not always the time of symptom onset. If symptoms had persisted for longer than average in our population, our findings may overestimate the risk of early birth. Of the women with a diagnosis of a UTI, only $21.1 \%$ had a code for the causative organism. It was unknown how many of the women had a culture that was not documented in the ICD9 diagnostic codes. Different species of bacteria have different pathogenic factors that may increase or decrease risk of early birth. In fact, the percent PTB by organism identified in our population ranged from 15.2 to $28.8 \%$, indicating that some organisms may result in worse outcomes than others. Finally, the California dataset did not have information regarding treatment. Based on findings in the Iowa dataset, it is likely that antibiotic treatment does not fully eliminate risk of PTB associated with a UTI.

To conclude, our findings suggest that UTIs are associated with PTB, particularly a spontaneous PTB. This risk is elevated regardless of the trimester of pregnancy and whether they received antibiotic treatment. Women hospitalized with a UTI during their second trimester were at greatest risk, suggesting that more severe infections further elevate the risk during this time period. Women should be advised of this risk and encouraged to seek medical care if they develop symptoms consistent with a UTI.

\section{Conclusion}

Women with a UTI during pregnancy were at elevated risk of a birth $<32$ weeks, 32 to 36 weeks, and 37 to 38 weeks (adjusted risk ratios [aRRs] 1.1-1.4). Of the women with a diagnostic code for multiple bacterial species, $28.8 \%$ had a PTB. A UTI diagnosis elevated risk of PTB regardless of antibiotic treatment (aRR 1.4 for treated, aRR 1.5 for untreated). This association of preterm birth and UTIs during pregnancy is present regardless of the trimester of pregnancy, type of type of preterm birth, and antibiotic treatment.

\section{Conflict of Interest}

None.

\section{Acknowledgments}

Supported by the California Preterm Birth Initiative within the University of California San Francisco. An abstract of this work was presented as a poster at the Society of Maternal Fetal Medicine's 39th Annual Pregnancy Meeting in February 2019.

\section{References}

1 Delzell JE Jr, Lefevre ML. Urinary tract infections during pregnancy. Am Fam Physician 2000;61(03):713-721

2 Lucas MJ, Cunningham FG. Urinary infection in pregnancy. Clin Obstet Gynecol 1993;36(04):855-868

3 Committee on Practice Bulletins-Obstetrics, The American College of Obstetricians and Gynecologists. Practice bulletin no. 130: prediction and prevention of preterm birth. Obstet Gynecol 2012; 120(04):964-973

4 National Institute for Health and Clinical Excellence. Antenatal care. NICE clinical guideline 2010. Access December 09, 2019 at: https:// www.nice.org.uk/guidance/qs22/documents/antenatal-care5

5 U.S. Preventive Services Task Force. Screening for asymptomatic bacteriuria in adults: reaffirmation recommendation statement. Am Fam Physician 2010;81(04):505

6 Moore A, Doull M, Grad R, et al;Canadian Task Force on Preventive Health Care. Recommendations on screening for asymptomatic bacteriuria in pregnancy. CMAJ 2018;190(27):E823-E830

7 Nicolle LE, Bradley S, Colgan R, Rice JC, Schaeffer A, Hooton TMInfectious Diseases Society of America American Society of Nephrology American Geriatric Society. Infectious Diseases Society of America guidelines for the diagnosis and treatment of asymptomatic bacteriuria in adults. Clin Infect Dis 2005;40(05): 643-654

8 Agger WA, Siddiqui D, Lovrich SD, et al. Epidemiologic factors and urogenital infections associated with preterm birth in a midwestern U.S. population. Obstet Gynecol 2014;124(05):969-977

9 Bánhidy F, Acs N, Puhó EH, Czeizel AE. Pregnancy complications and birth outcomes of pregnant women with urinary tract infections and related drug treatments. Scand J Infect Dis 2007; 39(05):390-397

10 Farkash E, Weintraub AY, Sergienko R, Wiznitzer A, Zlotnik A, Sheiner E. Acute antepartum pyelonephritis in pregnancy: a critical analysis of risk factors and outcomes. Eur J Obstet Gynecol Reprod Biol 2012;162(01):24-27

11 Mazor-Dray E, Levy A, Schlaeffer F, Sheiner E. Maternal urinary tract infection: is it independently associated with adverse pregnancy outcome? J Matern Fetal Neonatal Med 2009;22(02):124-128

12 Schieve LA, Handler A, Hershow R, Persky V, Davis F. Urinary tract infection during pregnancy: its association with maternal morbidity and perinatal outcome. Am J Public Health 1994;84(03):405-410

13 Chen YK, Chen SF, Li HC, Lin HC. No increased risk of adverse pregnancy outcomes in women with urinary tract infections: a nationwide population-based study. Acta Obstet Gynecol Scand 2010;89(07):882-888

14 Morken NH, Gunnes N, Magnus P, Jacobsson B. Risk of spontaneous preterm delivery in a low-risk population: the impact of 
e12 Risk of Early Birth among Women with a UTI Baer et al.

maternal febrile episodes, urinary tract infection, pneumonia and ear-nose-throat infections. Eur J Obstet Gynecol Reprod Biol 2011;159(02):310-314

15 Goldenberg RL, Hauth JC, Andrews WW. Intrauterine infection and preterm delivery. N Engl J Med 2000;342(20):1500-1507

16 Anderson BL, Simhan HN, Simons KM, Wiesenfeld HC. Untreated asymptomatic group B streptococcal bacteriuria early in pregnancy and chorioamnionitis at delivery. Am J Obstet Gynecol 2007;196(06):524.e1-524.e5

17 Meis PJ, Michielutte R, Peters TJ, et al. Factors associated with preterm birth in Cardiff, Wales. I. Univariable and multivariable analysis. Am J Obstet Gynecol 1995;173(02):590-596

18 Baer RJ, Norton ME, Shaw GM, et al. Risk of selected structural abnormalities in infants after increased nuchal translucency measurement. Am J Obstet Gynecol 2014;211(06):675.e1-675.e19

19 Agency for Healthcare Resarch and Quality. Prevention Quality Indicators \#12 (PQI \#12) Urinary Tract Infection Admission Rate. 2015. Accessed December 09, 2019 at: https://www.qualityindicators.ahrq.gov/Downloads/Modules/PQI/V50-ICD10/TechSpecs/PQI\%2012\%20Urinary\%20Tract\%20Infection\%20Admission \%20Rate.pdf
20 Jelliffe-Pawlowski LL, Baer RJ, Blumenfeld YJ, et al. Maternal characteristics and mid-pregnancy serum biomarkers as risk factors for subtypes of preterm birth. BJOG 2015;122(11):1484-1493Q8

21 Kotelchuck M. An evaluation of the Kessner adequacy of prenatal care index and a proposed adequacy of prenatal care utilization index. Am J Public Health 1994;84(09):1414-1420

22 Matuszkiewicz-Rowińska J, Małyszko J, Wieliczko M. Urinary tract infections in pregnancy: old and new unresolved diagnostic and therapeutic problems. Arch Med Sci 2015;11(01):67-77

23 Romero R, Grivel JC, Tarca AL, et al. Evidence of perturbations of the cytokine network in preterm labor. Am J Obstet Gynecol 2015; 213(06):836.e1-836.e18

24 Jafri S, Ormiston ML. Immune regulation of systemic hypertension, pulmonary arterial hypertension, and preeclampsia: shared disease mechanisms and translational opportunities. Am J Physiol Regul Integr Comp Physiol 2017;313(06):R693-R705

25 Schneeberger C, Geerlings SE, Middleton P, Crowther CA. Interventions for preventing recurrent urinary tract infection during pregnancy. Cochrane Database Syst Rev 2012;11:CD009279

26 Smaill F, Vazquez JC. Antibiotics for asymptomatic bacteriuria in pregnancy. Cochrane Database Syst Rev 2007;(02):CD000490 
Appendix 1 Diagnostic codes used from emergency department and hospital discharge records

\begin{tabular}{|c|c|}
\hline Diagnosis & ICD-9/10 diagnostic code \\
\hline Asymptomatic bacteriuria & $\begin{array}{l}\text { 646.5 Asymptomatic bacteriuria in pregnancy } \\
\text { O23.9 Other and unspecified genitourinary tract infection in pregnancy }\end{array}$ \\
\hline Urinary tract infection & $\begin{array}{l}\text { 590.1 Acute pyelonephritis } \\
\text { N10 Acute tubulo-interstitial nephritis } \\
\text { 595.0 Acute cystitis } \\
\text { N30.0 Acute cystitis } \\
\text { 595.9 Cystitis, unspecified } \\
\text { N30.9 Cystitis, unspecified } \\
\text { 597.80 Urethritis, unspecified } \\
\text { N34.1 Nonspecific urethritis } \\
\text { N34.2 Other urethritis } \\
\text { 599.0 Urinary tract infection, site not specified } \\
\text { N39.0 Urinary tract infection, site not specified } \\
\text { 646.6 Infections of genitourinary tract in pregnancy complicating pregnancy, } \\
\text { childbirth, and the puerperium } \\
\text { O23.0 Infections of kidney in pregnancy } \\
\text { O23.1 Infections of bladder in pregnancy } \\
\text { O23.2 Infections of urethra in pregnancy } \\
\text { O23.3 Infections of other parts of urinary tract in pregnancy } \\
\text { O23.4 Unspecified infection of urinary tract in pregnancy }\end{array}$ \\
\hline Pyelonephritis & $\begin{array}{l}\text { 590.1 Acute pyelonephritis } \\
\text { O23.0 Infections of kidney in pregnancy } \\
\text { N10 Acute tubulo-interstitial nephritis }\end{array}$ \\
\hline $\begin{array}{l}\text { Drug or alcohol } \\
\text { dependence/abuse }\end{array}$ & $\begin{array}{l}\text { 648.3 Drug dependence complicating pregnancy, childbirth, and the puerperium } \\
305 \text { Nondependent abuse of drugs } \\
304 \text { Drug dependence } \\
303 \text { Alcohol dependence syndrome } \\
\text { P04.4 Fetus and newborn affected by maternal use of drugs of addiction } \\
\text { F10 Mental and behavioral disorders due to use of alcohol } \\
\text { F11 Mental and behavioral disorders due to use of opioids } \\
\text { F12 Mental and behavioral disorders due to use of cannabinoids } \\
\text { F13 Mental and behavioral disorders due to use of sedatives or hypnotics } \\
\text { F14 Mental and behavioral disorders due to use of cocaine } \\
\text { F15 Mental and behavioral disorders due to use of other stimulants, including caffeine } \\
\text { F16 Mental and behavioral disorders due to use of hallucinogens } \\
\text { F18 Mental and behavioral disorders due to use of volatile solvents } \\
\text { F19 Mental and behavioral disorders due to multiple drug use and } \\
\text { use of other psychoactive substances }\end{array}$ \\
\hline Hypertensive disorder & $\begin{array}{l}642 \text { Hypertension complicating pregnancy, childbirth, and the puerperium } \\
\text { O1 Edema, proteinuria, and hypertensive disorders in pregnancy, } \\
\text { childbirth, and the puerperium }\end{array}$ \\
\hline Diabetes & $\begin{array}{l}\text { 250 Diabetes mellitus } \\
\text { 648.0 Diabetes mellitus } \\
\text { 648.8 Abnormal glucose tolerance } \\
\text { P70.0 Syndrome of infant of mother with gestational diabetes } \\
\text { P70.1 Syndrome of infant of a diabetic mother } \\
\text { O24 Diabetes mellitus in pregnancy }\end{array}$ \\
\hline E. coli & $\begin{array}{l}\text { 041.4 Escherichia coli } \\
038.42 \text { Escherichia coli } \\
\text { B96.2 Escherichia coli }(E . \text { coli) as the cause of diseases classified to other chapters }\end{array}$ \\
\hline Proteus & $\begin{array}{l}\text { 041.6 Proteus (mirabilis) (morganii) } \\
\text { B96.4 Proteus (mirabilis)(morganii) as the cause of diseases classified to other chapters }\end{array}$ \\
\hline Pseudomonas & $\begin{array}{l}\text { 041.7 Pseudomonas } \\
038.43 \text { Pseudomonas } \\
\text { B96.5 Pseudomonas (aeruginosa) as the cause of diseases classified to other chapters }\end{array}$ \\
\hline Other/unspecified & $\begin{array}{l}\text { 038.44 Serratia } \\
038.49 \text { Other } \\
038.40 \text { Gram-negative organism, unspecified } \\
038.41 \text { Hemophilus influenzae }(H . \text { influenzae) } \\
\text { B96.3 Hemophilus influenzae }(H \text {. influenzae) as the cause of diseases classified to other chapters }\end{array}$ \\
\hline
\end{tabular}


e14 Risk of Early Birth among Women with a UTI Baer et al.

Appendix 1 (Continued)

\begin{tabular}{|c|c|}
\hline Diagnosis & ICD-9/10 diagnostic code \\
\hline & $\begin{array}{l}\text { 041.84 Other anaerobes } \\
\text { 041.85 Other gram-negative organisms } \\
\text { 041.86 Helicobacter pylori }(H \text {. pylori) } \\
\text { 038.9 Unspecified septicemia } \\
\text { 041.9 Bacterial infection, unspecified } \\
\text { B96.6 Bacillus fragilis [B. fragilis] as the cause of diseases classified to other chapters } \\
\text { B96.8 Other specified bacterial agents as the cause of diseases classified to other chapters }\end{array}$ \\
\hline Klebsiella & $\begin{array}{l}041.3 \text { Friedländer's bacillus } \\
\text { B96.1 Klebsiella pneumoniae [K. pneumoniae] as the cause of diseases } \\
\text { classified to other chapters }\end{array}$ \\
\hline Streptococcus & $\begin{array}{l}\text { 041.0 Streptococcus } \\
\text { 038.0 Streptococcal septicemia } \\
\text { B95.0 Streptococcus, group A, as the cause of diseases classified to other chapters } \\
\text { B95.1 Streptococcus, group B, as the cause of diseases classified to other chapters } \\
\text { B95.3 Streptococcus pneumoniae as the cause of diseases classified to other chapters } \\
\text { B95.4 Other Streptococcus as the cause of diseases classified to other chapters } \\
\text { B95.5 Unspecified Streptococcus as the cause of diseases classified to other chapters }\end{array}$ \\
\hline Enterococcus & $\begin{array}{l}\text { 041.04 Streptococcus Group D (Enterococcus) } \\
\text { B95.2 Streptococcus group D and enterococcus as the cause of diseases } \\
\text { classified to other chapters }\end{array}$ \\
\hline Staphylococcus & $\begin{array}{l}\text { 038.1 Staphylococcal septicemia } \\
\text { 041.1 Staphylococcus } \\
\text { B95.6 Staphylococcus aureus as the cause of diseases classified to other chapters } \\
\text { B95.7 Other Staphylococcus as the cause of diseases classified to other chapters } \\
\text { B95.8 Unspecified Staphylococcus as the cause of diseases classified to other chapters }\end{array}$ \\
\hline $\begin{array}{l}\text { Preterm birth } \\
\text { (lowa population only) }\end{array}$ & $\begin{array}{l}\text { 644.21 Early onset of delivery } \\
\text { O60.1 Preterm spontaneous labor with preterm delivery }\end{array}$ \\
\hline
\end{tabular}

Abbreviation: ICD, International Classification of Disease-Ninth Revision. 